\title{
Gambaran gangguan pemusatan perhatian pada remaja gamers di Manado periode November 2014 - Desember 2014
}

\author{
${ }^{1}$ Kevin A. Kaseger \\ ${ }^{2}$ Herlyani Khosama \\ ${ }^{2}$ Corry N. Mahama
}

\author{
${ }^{1}$ Kandidat Skripsi Fakultas Kedokteran Universitas Sam Ratulangi Manado \\ ${ }^{2}$ Bagian Neurologi Fakultas Kedokteran Universitas Sam Ratulangi Manado \\ Email: kaseger_kevin@ymail.com
}

\begin{abstract}
Attention deficit disorders (ADD) is a medical disorder that has its own characteristics and tends to be hereditary. Generally, there are three types of behavior associated with this disorder, namely: lack of surrounding attention (inattentiveness), easily distracted (distractibility), and impulsive attitude (impulsiveness). This study was aimed to obtain the prevalence of ADD among adolescent gamers. This was a descriptive-quantitative study with a cross-sectional design. This study was carried out on regular gamers aged 12-15 years who were students of junior high schools. The total respondents in this study were 30 regular gamer teenagers. The digit span, backward digit span, and the stroop test were performed on all respondents. The results showed that among teenagers who played video games more than 1 time per week there were $36.67 \%$ with attention deficit disorders. Keywords: ADD, videogames, adolescents, digit span, backward digit span, stroop test
\end{abstract}

\begin{abstract}
Abstrak: Gangguan pemusatan perhatian (GPP) adalah suatu kelainan medis yang memiliki ciri tersendiri dan cenderung merupakan keturunan. Secara umum terdapat tiga jenis perilaku yang dikaitkan dengan kelainan ini, yaitu: sikap kurang memperhatikan sekeliling (inattentiveness), mudah terganggu (distractibility), dan sikap menurutkan kata hati (impulsiveness). Penelitian ini bertujuan untuk mendapatkan prevalensi GPP di kalangan remaja gamers. Jenis penelitian ialah deskriptif-kuantitatif dengan desain potong lintang. Penelitian ini dilakukan pada remaja regular gamers berusia 12-15 tahun yang masih duduk di bangku SMP dengan total 30 remaja regular gamers sebagai responden. Pada responden dilakukan pemeriksaan digit span, backward digit span, dan stroop test. Hasil penellitian memperlihatkan bahwa dari ketiga macam pemeriksaan tersebut yang dilakukan pada remaja yang bermain videogame lebih dari 1 kali per minggu didapatkan GPP rata-rata 36,67\%.
\end{abstract}

Kata kunci: GPP, videogame, remaja, digit span, backward digit span, stroop test.

Gangguan pemusatan perhatian (GPP) adalah suatu kelainan medis yang dapat dikenali dan memiliki ciri tersendiri yang cenderung merupakan keturunan. Secara umum terdapat tiga jenis perilaku yang dikaitkan dengan kelainan ini, yaitu: sikap kurang memperhatikan sekeliling (inattentiveness), mudah terganggu, (distractibility) dan sikap menurutkan kata hati (impulsiveness). ${ }^{1}$
Pentecost menjelaskan lebih lanjut tentang gejala-gejala pada anak GPP. Kurangnya pemusatan perhatian menyebabkan anak lebih mudah terganggu dibandingkan anak-anak lainnya, dan sama sekali tidak bisa berkonsentrasi pada tugastugasnya, akibatnya prestasi sekolah buruk dan mengganggu anak-anak lain. Impulsivitas ditandai dengan selalu melakukan tindakan yang berisiko, berbuat 
tanpa berpikir dahulu seolah-olah tidak sadar terhadap akibatnya, dan seolah-olah tidak mendengar. ${ }^{2}$

Di era sekarang ini, videogame sangat berkembang pesat dibandingkan era-era sebelumnya. Videogame telah menjadi bagian yang tidak terpisahkan dari keseharian remaja sebagai sarana bersenangsenang. Funk mengatakan bahwa frekuensi bermain videogame pada remaja cukup tinggi. ${ }^{3} \mathrm{Hal}$ ini juga terlihat dari penelitian yang dilakukan oleh Lenhart et al. yang menyebutkan bahwa sekitar $97 \%$ remaja bermain videogame, khususnya remaja awal. $^{4,5}$

Menurut Papalia et al. ${ }^{5}$, masa remaja adalah masa transisi perkembangan antara masa kanak-kanak dan masa dewasa yang pada umumnya dimulai pada usia 12 atau 13 tahun dan berakhir pada usia akhir belasan tahun atau awal dua puluhan tahun. Jika dilihat dari segi usia, biasanya remaja duduk di bangku sekolah. Pada rentang usia ini remaja berada pada masa pendidikan menengah yaitu Sekolah Menengah Pertama (SMP) dan Sekolah Menengah Umum (SMU). ${ }^{6}$

Malone mengidentifikasikan tiga hal yang menjadi alasan mengapa seseorang bermain videogame yaitu fantasi, tantangan, dan rasa ingin tahu. Berdasarkan sebuah survei yang telah dilakukan, Kirremuir dan McFarlane menemukan 4 alasan utama mengapa seseorang bermain videogame yaitu: ${ }^{7,8}$

1. Bermain videogame merupakan hal yang menyenangkan.

2. Bermain videogame merupakan hal yang memberikan tantangan.

3. Bermain videogame sebagai sarana berinteraksi dengan teman dan keluarga.

4. Videogame menyediakan hiburan yang sesuai dengan uang yang dikeluarkan.

Sadar atau tidak sadar, dampak dari kebiasaan bermain games ini dapat menyebabkan munculnya suatu gangguan pemusatan perhatian dan hiperaktivitas di kalangan remaja yang bermain videogame. Hal ini dibuktikan oleh Bioulac et al. yang menyatakan bahwa adanya hubungan bermakna antara videogame dengan peningkatan GPP. $^{9}$

\section{METODE PENELITIAN}

Jenis penelitian ini ialah deskriptifkuantitatif dengan desain potong lintang untuk mendapatkan prevalensi GPP/ hiperaktivitas di kalangan remaja screengamers. Penelitian ini dilakukan di Warung Internet (Warnet) di Manado dengan waktu pelaksanaan penelitian pada bulan November 2014 sampai bulan Desember 2014.

Populasi penelitian ini ialah remaja yang bermain videogame di warnet Manado yang masih duduk di bangku SMP. Teknik pengambilan sampel ialah pengambilan sampel tidak acak (Non-probability sampling) dengan teknik consecutive sampling sebanyak 30 responden.

Pada penelitian ini dilakukan skrining remaja yang bermain videogame dengan lama waktu bermain perminggu minimal lebih dari 1 kali per minggu. Skrining dilakukan dengan kuesioner yang sudah disusun terlebih dahulu kemudian dilakukan tes forward digit span, backward digit span, dan stroop test untuk mendapatkan data yang diperlukan.

\section{HASIL PENELITIAN}

Penelitian ini dilakukan pada remaja regular gamers berusia 12-15 tahun yang masih duduk di bangku SMP. Total jumlah responden yang diteliti ialah 30 remaja.

Tabel 1 memperlihatkan rerata usia remaja yang bermain videogame lebih dari 1 kali per minggu ialah 13,5 tahun.

Tabel 1. Jumlah presentase dan rerata usia dari responden

\begin{tabular}{ccc}
\hline \multirow{2}{*}{ Usia (tahun) } & \multicolumn{2}{c}{ Jumlah } \\
\cline { 2 - 3 } & $\mathbf{N}$ & $\mathbf{\%}$ \\
\hline 12 & 3 & 10 \\
13 & 10 & 33 \\
14 & 16 & 54 \\
15 & 1 & 3 \\
Total & 30 & 100 \\
Rerata & \multicolumn{2}{c}{13,5} \\
\hline
\end{tabular}

Berdasarkan Tabel 2 didapatkan lakilaki lebih banyak dibandingkan perempuan. 
Laki-laki sebanyak 23 responden (76\%) dan perempuan sebanyak 7 responden $(24 \%)$.

Tabel 2. Jumlah dan presentase jenis kelamin dari responden

\begin{tabular}{ccc}
\hline \multirow{2}{*}{ Jenis kelamin } & \multicolumn{2}{c}{ Jumlah } \\
& $\mathrm{N}$ & $\%$ \\
\hline Laki-laki & 23 & 76 \\
Perempuan & 7 & 24 \\
Total & 30 & 100 \\
\hline
\end{tabular}

Berdasarkan Tabel 3 dapat dilihat bahwa remaja yang memiliki waktu tidur kurang dari 8 jam sebanyak $40 \%$ dan remaja yang memiliki waktu tidur $\geq 8$ jam sebanyak $60 \%$.

Tabel 3. Waktu istirahat/tidur responden

\begin{tabular}{ccc}
\hline \multirow{2}{*}{ Waktu istirahat/tidur } & \multicolumn{2}{c}{ Jumlah } \\
& $\mathrm{N}$ & $\%$ \\
\hline$\geq 8$ jam & 18 & 60 \\
$<8$ jam & 12 & 40 \\
Total & 30 & 100 \\
\hline
\end{tabular}

Berdasarkan Tabel 4 dapat dilihat bahwa dengan tes forward digit span didapatkan 23,33\% remaja mengalami GPP dengan jeni kelamin laki-laki berusia 14 tahun yang paling banyak mengalami GPP.

Berdasarkan Tabel 5 dapat dilihat bahwa dengan menggunakan tes backward digit span didapatkan $36,67 \%$ responden mengalami GPP dengan laki-laki berusia 14 tahun paling banyak mengalami GPP.

Berdasarkan Tabel 6 dapat dilihat bahwa dengan menggunakan stroop test didapatkan $50 \%$ responden mengalami GPP. $\mathrm{I}_{\mathrm{R}}$ merupakan standard pengukuran stroop test dengan rumus $\mathrm{I}_{\mathrm{R}}=\mathrm{CW} / \mathrm{C}$. CW yaitu Colour-word Score dan C yaitu Colour Score.

Berdasarkan Tabel 7 dapat dilihat hasil rata-rata dari tiga tes gangguan pemusatan yang dilakukan pada remaja regular gamers. Hasilnya 36,67\% rata-rata remaja ditemukan mengalami gangguan pemusatan perhatian dan $63,33 \%$ rata-rata dari remaja tersebut tidak mengalami gangguan pemusatan perhatian.

Tabel 4. Hasil tes forward digit span berdasarkan usia

\begin{tabular}{cccccc}
\hline $\begin{array}{c}\text { Usia } \\
\text { (tahun) }\end{array}$ & Jenis kelamin & Hasil Span & J & $\%$ & GPP \\
\hline \multirow{3}{*}{12} & Laki-laki & $\geq 6$ & 2 & 6,6 & - \\
& & $\leq 5$ & - & - & - \\
& Perempuan & $\geq 6$ & 1 & 3,3 & - \\
& & $\leq 5$ & - & - & - \\
\multirow{2}{*}{13} & Laki-laki & $\geq 6$ & 5 & 16,67 & - \\
& & $\leq 5$ & 3 & 10 & 10 \\
& Perempuan & $\geq 6$ & 2 & 6,6 & - \\
& & $\leq 5$ & - & - & - \\
\multirow{2}{*}{14} & Laki-laki & $\geq 6$ & 8 & 26,6 & - \\
& & $\leq 5$ & 4 & 13,3 & 13,3 \\
& Perempuan & $\geq 6$ & 4 & 13,3 & - \\
& & $\leq 5$ & - & - & - \\
15 & Laki-laki & $\geq 6$ & 1 & 3,3 & - \\
& & $\leq 5$ & - & - & - \\
Total & Perempuan & $\geq 6$ & - & - & - \\
& & $\leq 5$ & - & - & - \\
\hline
\end{tabular}


Kaseger, Khosama, Maham: Gambaran gangguan pemusatan...

Tabel 5. Hasil tes dengan menggunakan tes backward digit span

\begin{tabular}{cccccc}
\hline Usia (tahun) & \multirow{2}{*}{ Jenis kelamin } & Hasil Span & \multicolumn{2}{c}{ Jumlah } & GPP \\
\hline \multirow{3}{*}{12} & Laki-laki & $\geq 5$ & 2 & 6,6 & - \\
& & $\leq 4$ & - & - & - \\
& Perempuan & $\geq 5$ & 1 & 3,3 & - \\
& & $\leq 4$ & - & - & - \\
13 & Laki-laki & & 4 & 13,3 & - \\
& & $\leq 4$ & 4 & 13,3 & 13,3 \\
& Perempuan & $\geq 5$ & 2 & 6,6 & - \\
& & $\leq 4$ & - & - & - \\
14 & Laki-laki & $\geq 5$ & 5 & 16,6 & - \\
& & $\leq 4$ & 7 & 23,3 & 23,3 \\
& Perempuan & $\geq 5$ & 4 & 13,3 & - \\
& & $\leq 4$ & - & - & - \\
15 & Laki-laki & $\geq 5$ & 1 & 3,3 & - \\
& & $\leq 4$ & - & - & - \\
Total & Perempuan & $\geq 5$ & - & - & - \\
& & $\leq 4$ & - & - & - \\
& & & 30 & 100 & 36,6 \\
\hline
\end{tabular}

Tabel 6. Hasil tes dengan menggunakan stroop test

\begin{tabular}{|c|c|c|c|c|c|}
\hline \multirow{2}{*}{ Usia (tahun) } & \multirow{2}{*}{ Jenis kelamin } & \multirow[b]{2}{*}{$\mathbf{I}_{\mathbf{R}}$} & \multicolumn{2}{|c|}{ Jumlah } & \multirow{2}{*}{ GPP } \\
\hline & & & $\mathrm{N}$ & $\%$ & \\
\hline \multirow{4}{*}{12} & \multirow{2}{*}{ Laki-laki } & $<0,56$ & - & - & - \\
\hline & & $\geq 0,56$ & 2 & 6,6 & - \\
\hline & \multirow{2}{*}{ Perempuan } & $<0,56$ & - & - & - \\
\hline & & $\geq 0,56$ & 1 & 3,3 & - \\
\hline \multirow{4}{*}{13} & \multirow{2}{*}{ Laki-laki } & $<0,56$ & 5 & 16,6 & 16,6 \\
\hline & & $\geq 0,56$ & 3 & 10 & - \\
\hline & \multirow{2}{*}{ Perempuan } & $<0,56$ & 1 & 3,3 & 3,3 \\
\hline & & $\geq 0,56$ & 1 & 3,3 & - \\
\hline \multirow{4}{*}{14} & \multirow{2}{*}{ Laki-laki } & $<0,56$ & 8 & 26,6 & 26,6 \\
\hline & & $\geq 0,56$ & 4 & 13,3 & - \\
\hline & \multirow{2}{*}{ Perempuan } & $<0,56$ & - & - & - \\
\hline & & $\geq 0,56$ & 4 & 13,3 & - \\
\hline \multirow{4}{*}{15} & \multirow{2}{*}{ Laki-laki } & $<0,56$ & 1 & 3,3 & 3,3 \\
\hline & & $\geq 0,56$ & - & - & - \\
\hline & \multirow{2}{*}{ Perempuan } & $<0,56$ & - & - & - \\
\hline & & $\geq 0,56$ & - & - & - \\
\hline Total & & & 30 & 100 & 50 \\
\hline
\end{tabular}

Tabel 7. Hasil rerata dari forward digit span, backward digit span, dan stroop test

\begin{tabular}{ccccc}
\hline Jenis tes & \multicolumn{2}{c}{ Mengalami GPP } & \multicolumn{2}{c}{ Tidak mengalami GPP } \\
& $\mathrm{N}$ & $\%$ & $\mathrm{~N}$ & $\%$ \\
\hline Forward Digit Span & 7 & 23,33 & 23 & 76,67 \\
Backward Digit Span & 11 & 36,67 & 19 & 63,33 \\
Stroop test & 15 & 50 & 15 & 50 \\
Rerata & 11 & 36,67 & 19 & 63,33 \\
\hline
\end{tabular}




\section{BAHASAN}

Penelitian ini dilakukan pada remaja regular gamers yang masih duduk di bangku sekolah menengah pertama dari kelas 1 sampai dengan kelas 3. Pada penelitian ini jumlah responden laki-laki lebih banyak dibandingkan perempuan. Hal ini mungkin karena penelitian ini dilakukan di tempat bermain game seperti warung internet. Ditemukan bahwa rerata usia para remaja yang sering bermain video games di warung internet ialah 13 tahun yang duduk di kelas II SMP. Hal ini dikarenakan para remaja yang duduk dikelas II SMP mungkin lebih mendapatkan kebebasan dari orang tua mereka dibandingkan yang duduk di kelas III SMP yaitu kelas ujian sedangkan kelas I merupakan tahap awal dalam sekolah sehingga orang tua lebih mengawasi anak-anak mereka.

Penelitian yang dilakukan oleh Chan dan Rabinowitz ${ }^{8}$ mengatakan bahwa hal ini belum pasti apakah bermain videogame lebih dari 1 jam per hari dapat meningkatkan gejala GPP atau apakah remaja dengan gejala GPP menghabiskan waktunya untuk bermain videogame. ${ }^{10}$ Hal tersebut masih perlu ditinjau lagi, seperti yang didapatkan dari kuesioner oleh peneliti, GPP tidak hanya pada remaja yang sering bermain videogame lebih dari 1 jam per hari, tetapi juga ada faktor lain yang menyebabkan terjadinya gangguan pemusatan yaitu pola tidur yang tidak teratur $<8$ jam dan sering menghabiskan waktu untuk bermain videogame.

Hasil dari pemeriksaan digit span yang dilakukan pada remaja memberikan hasil bahwa dengan backward digit span lebih besar persentase remaja yang memiliki GPP yaitu sebesar 37\% sedangkan dengan forward digit span sebesar $24 \%$ saja. Hal ini dikarenakan saat menjalani backward digit span responden lebih sulit untuk mengingat kembali angka-angka yang disebutkan daripada forward digit span. Backward digit span mengharuskan para remaja untuk mengingat kembali angkaangka yang diucapkan dari angka terakhir sampai angka pertama, sedangkan forward digit span sebaliknya. Dengan pemeriksaan stroop test didapatkan persentase yang lebih besar dibandingkan persentase dari forward dan backward digit span yaitu sebesar 50\%. Dari hasil ketiga pemeriksaan ini diketahui bahwa rerata sebesar 36,67\% dari remaja memiliki GPP dengan menggunakan forward digt span, backward digit span, dan stroop test.

Berdasarkan penelitian yang dilakukan oleh Chan dan Rabinowitz ${ }^{8}$ terdapat sekitar 3\% dari 72 orang remaja yang bermain videogame lebih dari 1 jam per hari mengalami GPP. Hasil penelitian tersebut menunjukkan bahwa belum tentu ada hubungan antara kebiasaan remaja bermain videogame lebih dari satu jam per hari dengan GPP. Hasil dari penelitian ini menunjukan oersentasse rerata remaja yang mengalami GPP ialah 36,67\% dari 30 remaja regular gamers. Dengan hasil yang demikian tidak dapat disimpulkan bermain videogame dapat menyebabkan GPP.

Keterbatasan penelitian ini ialah jumlah responden hanya 30 orang remaja yang sangat memengaruhi hasil penelitian. Juga tidak diteliti lebih lanjut mengenai kolerasi antara pola tidur dan jenis game yang dimainkan dengan terjadinya GPP.

\section{SIMPULAN}

Dari hasil penelitian dengan menggunakan tiga macam tes (forward digit span, backward digit span, dan stroop test) pada remaja yang bermain videogame lebih dari 1 kali per minggu didapatkan prevalensi gangguan pemusatan perhatian rata-rata $36,67 \%$.

\section{SARAN}

Untuk penelitian selanjutnya dianjurkan untuk melakukan penelitian serupa dengan jumlah responden yang lebih banyak dan menyeluruh serta mengikutsertakan pola tidur dan jenis game yang dimainkan.

Diusahakan menurunkan angka kejadian gangguan pemusatan perhatian pada remaja dengan melakukan penyuluhan kepada masyarakat, memperbanyak aktivitas fisik seperti olahraga dan mengurangi bermain game. 
DAFTAR PUSTAKA

1. Flanagen. ADHD kids. Attention deficit hyperaction disorder. Jakarta: Prestasi Pustaka Pelajar, 2005; p. 124.

2. Saputro D. ADHD (Attention Deficit/Hyperactivity Disorder) Jakarta: Sagung Seto, 2009.

3. Lenhart A, Kahne J, Middaugh E, Macgill ER, Evans C, Vitak J. Teens, video games, and civics. Washington, DC: Pew Internet \& American Life Project, 2008.

4. Gentile DA, Walsh DA. A normative study of family media habits. J Appl Develop Psychol. 2002;23:157-78

5. Papalia DE, Olds SW, Feldman RD. Human Development (10th ed.). Boston: McGraw-Hill, 2007.

6. Hamlen KR. Relationship between computer and video game play among upper elementary school students. Journal of Educational Computing Research DOI: 10.2190/EC.40.1.a.
Cleveland State University, 2009.

7. Kirremuir J, McFarlane A. Report 8: Literature review in games and learning. United Kingdom. Futurelab series, 2004; hal-00190453.

8. Chan PA, Rabinowitz T. A cross-sectional analysis of video games and attention deficit hyperactivity disorder symptoms in adolescents. Analas of General Psychiatry. 2006;5:16. DOI: 10.1186/1744-859X-5-16.

9. Maramis WE. Catatan Ilmu Kedokteran Jiwa. Surabaya: Airlangga University Press. 2005.

10. Philip AC, Rabinowitz T. A crosssectional analysis of video games and attention deficit hyperactivity disorder symptoms in adolescents. 24 Oktober 2006. Available from: http://www.annals-generalpsychiatry.com/contents/5/1/16. 